\title{
Research on Community Violence against Adolescents in Kosovo and related Variables
}

\author{
Armen Mustafa ${ }^{1}$
}

\begin{abstract}
The main purpose of this study was to conduct a research about the prevalence of violence against adolescents in the community, the types' prevalence of the violence; people who the most frequent use violence against adolescents, and the relationship between the types of violence and adolescents' demographic factors (gender, age and residence). The study was conducted in a sample of 608 adolescents from 10 Pristina's high schools, aged 15-18. For this study are used quantitative methods in fact survey type, while as the main instrument for data collection was used the questionnaire. The study's findings show that 9 out of 10 adolescents have experienced community violence (approximately $92 \%$ ), of whom 1 out of 9 adolescents high-level violence. From the types of violence, psychological violence is the most prevalent violence followed by violence against property, physical violence and sexual violence. The results of the study show that people who use more violence against adolescents are their peers, then adults and at the lowest level of violence are used by certain groups. Males, whether they are peers or adults, are the ones who use more violence against adolescents than females. When we talking about demographic characteristics and their relation to the types' prevalence of the violence, gender and residence of adolescents results to have an impact only on physical violence, but not on the other types of violence, while adolescents' age, being almost the same, results without any impact on the types' prevalence of the violence. Concerning these findings, have been addressed specific recommendations, the main purpose of which is to raise awareness and prevent violence in society in general and to children and youth in particular.
\end{abstract}

Keywords: Adolescents, violence, community, psychological violence, violence against property, physical violence and sexual violence

\section{INTRODUCTION}

Adolescents spend part of their time outside the home and school, respectively in the community. This mainly means that adolescents fulfil their free time with various activities, mostly with peers, but also with some daily obligations that may have or that can be charged by the family or others. Unlike activities and time spent at home and school, adolescents in the community are mostly not accompanied by a caretaker. This increases the risk for adolescents to be exposed and victimized against various acts of violence, where many of these actions can be dangerous and even fatal to their lives (Finkelhor, 2008; Pinheiro, 2006).

Violent actions to which adolescents are exposed and victimized in the community are different, ranging from the lightest to the most serious and pervasive forms of physical and sexual violence (Pinhero, 2006), then types of psychological violence such as: threats, fear and harassment (Hamby, Finkelhor, Ormrod, \& Turner, 2005) and finally types of violence related to conventional crimes

1PhD, AAB College, Prishtina, Kosovo, armenmustafa@gmail.com 
involving property damage such as theft, vandalism and robbery (Ellonen, Käriäinen, Salmi, \& Sariola, 2008).

Regarding the types' prevalence of the violence in the community, some studies put physical violence as the most prevalent in the community, then violence against property, psychological violence, and less prevalent sexual violence (Finkelhor, 2008; Ellonen et al., 2008). However, prevalence is even higher when it comes to exposure and being a witness of violence compared to being a direct victim (Margolin \& Gordis, 2004; Sheidow, Garman-Smith, Tolan, \& Henry, 2001). According to O'Keefe (1997), more than 1 out of 2 adolescents have witnessed or experienced various types of physical violence; about 1 out of 2 of vandalism and somewhat less than 1 out of 2 adolescents have witnessed or experienced various threats.

When we talking about violence-related factors, respectively adolescents' exposure to community violence and taking in consideration adolescences' age, the most frequent victims of violence against property (vandalism, robbery, and theft) are younger adolescents (12-13 years old), while physical and psychological violence (threats) are more pronounced at older age, respectively age 15 years (Ellonen et al., 2008).

As the most vulnerable to community violence are generally adolescents up to 14 years of age (Finkelhor \& Dziuba-Leatherman, 1994), while adolescents between the ages of 16 and 18 are more at risk of being exposed to serious types of violence in the community (Salzinger, Feldman, Stockhammer, \& Hood, 2002). Viewed from gender perspective, boys are generally those who report more violence than girls (Ellonen et al, 2008; O'Keefe, 1997; Salzinger et al, 2002). However, this somehow depends on the type of violence, because girls are more at risk of experiencing sexual violence (Finkelhor, 2008, Pinheiro, 2006). Whereas, viewed from a rural-urban point of view, there are big cities and deeper parts of cities where adolescents experience more violence than on rural areas (Sheidow et al, 2001; Finkelhor \& Dziuba-Leatherman, 1994).

Family and family structure are also considered important factors on exposure and victimization of adolescents against violence in the community. According to some of the studies, adolescents who live with one parent generally have reported the higher level of victimization compared to those living with the whole family (Salzinge et al., 2002; Finkelhor, Ormrod, Turner, \& Hamby, 2005). Also, socioeconomic factors, such as poverty, income levels, and inequality between social levels, are also closely related to community-based violence against adolescents (Finkelhor \& Dziuba-Leatherman, 1994, Pinheiro, 2006).

The main purpose of the study was to study the prevalence of violence, the types of violence exercised in the community against adolescents; to understand who are the most frequent perpetrators of violence and the relationship between the types of the violence and the demographic characteristics of adolescents. This study is part of a comprehensive study on violence against children in Kosovo society, where besides community violence also the social violence has been treated. 


\section{METHOD}

The study is based on a quantitative methodology of the survey type and questionnaire as the main instrument for data collection. The study sample includes adolescents aged 15-18, coming from 10 high schools in Pristina. From this sample, were selected samples of 608 adolescents, based on the probability method of simple casual sampling, based on $95 \%$ confidence level and $5 \%$ error margin.

\section{Data Collection Tools}

The questionnaire for data collection is an instrument prepared specifically for this study and is based on the UN report on violence against children (Pinheiro, 2006), in which report, when talking about violence in the community, then is talked about three types of violence: physical violence, psychological violence, and sexual violence. These 3 types of violence have been added the 4 th type of violence that is the violence against adolescents' property, based on the "The Juvenile Victimisation Questionnaire" instrument (Hamby, et al., 2005). The questionnaire is divided in two general parts: demographic and violence part. The violence part of questionnaire includes closed-ended questions, based on four (4) types of violence and four (4) questions are posed for each type of violence, where subjects were able to select an answer from 1 (never) to 5 (at least once a week). An example of the questions is: "In the district where you live, or even beyond, have you ever experienced things such as damage and destruction of personal belongings (clothes, bags, etc.)?" The Alpha Cronbach confidence interval of the questionnaire was conducted too, where the total value of all questions about community violence was $\alpha=0.784$.

To apply the questionnaire, subjects (respondents) have been initially informed about the purpose and the consent was obtained by both, the respondents and the institutions (schools), where the questionnaire has been administered. The administration of questionnaire was done within a 40 minutes timeframe and afterward the data from the questionnaire have been analysed through SPSS 22

\section{RESULTS}

\section{Prevalence of community violence against adolescent and its types}

The data about the prevalence of violence were analysed in the way that initially violence-related responses are grouped into 3 groups:

- Group I that corresponds to zero (0) level of violence, where are grouped the answers in which respondents answered "never (1)";

- Group II refers to violence which is considered as low-level violence where are grouped the answers with 2 (up to once (1) a year) and 3 - at least twice (2) a year", and

- Group III has to do with violence which is considered as high-level violence, where answers are grouped with 4 - at least once a month and 5 - at least once a week 


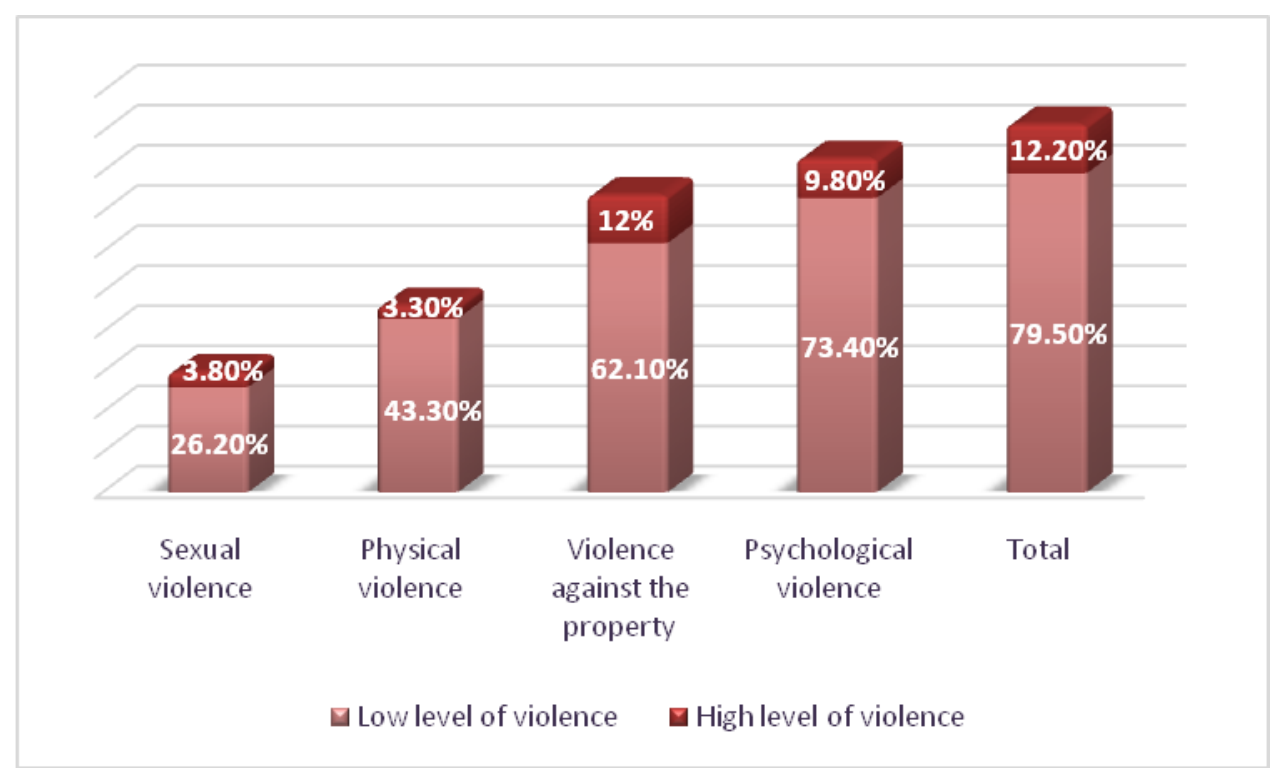

Figure 1. Violence Prevalence against Adolescents in the Community

Generally, the results of the study show that the prevalence of community violence against adolescents is very high, where more than 9 out of 10 adolescents have experienced community violence throughout their lives (91.7\%). From these, high-level violence have experienced more than 1 in 9 adolescents $(12.2 \%)$, while low-level is approximately 8 in 10 adolescents (79.5\%). Among the types of violence, the results show that psychological violence is more common among adolescents in the community $(83.2 \%)$, from which $9.8 \%$ of adolescents experienced this at high-level. Then comes the violence that has to do with the damage and destruction of property (64.2\%), which $62.1 \%$ of adolescents have experienced low-level, and $12 \%$ of them have experienced high-level of violence. Physical violence is the type that is less experienced by adolescents $(46 / 6 \%)$, at low-level of violence $(43.3 \%)$ and at high-level of violence (3.3\%). At a lower level than physical violence is sexual violence (30\%), where low-level is experienced by $26.2 \%$ and high-level is experienced by $3.8 \%$ of adolescents.

\section{Perpetrators of violence in the community}

In relation to persons who have exercised violence more often, in the questionnaire subjects were asked whether they were adults, peers, or have been certain groups (bands), even identifying their gender in cases when they were individuals. 


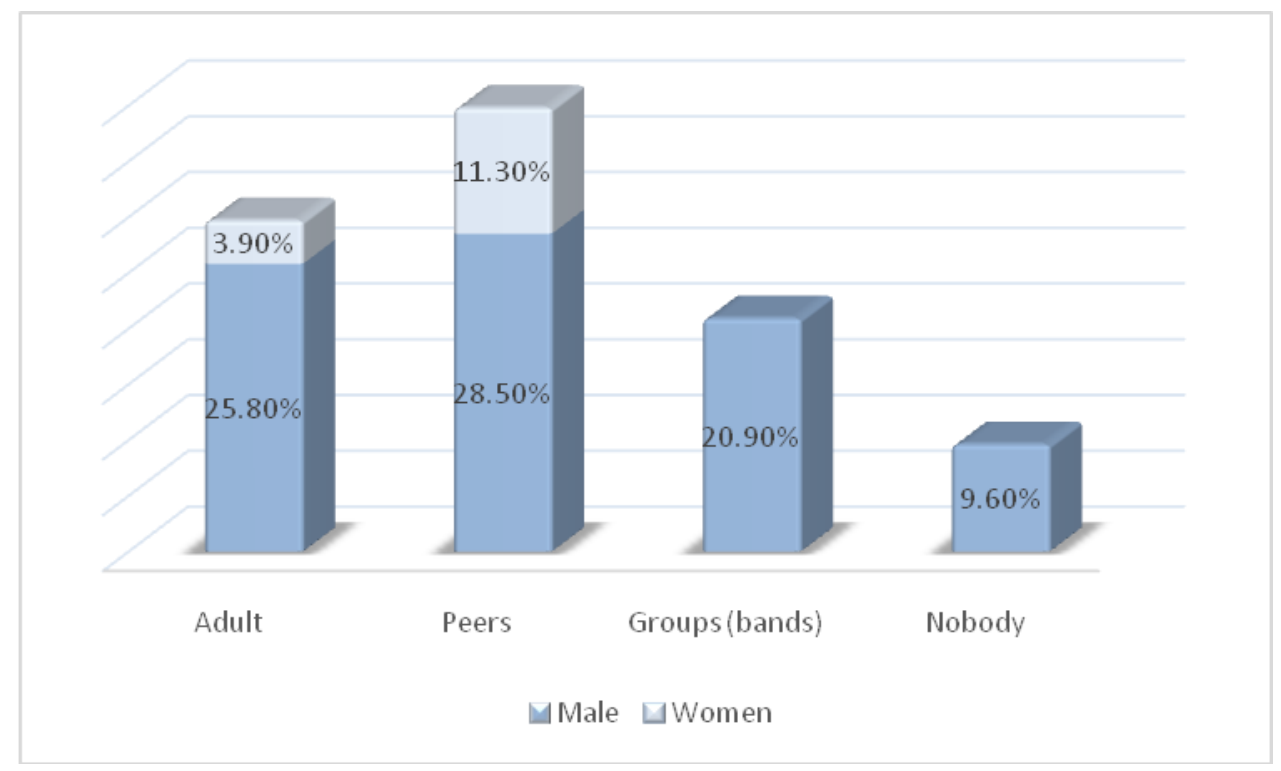

Figure 2. Perpetrators of Violence against Adolescents in the Community

Adolescents going through different periods of life, respectively passing from one level of education to the next level, from one place to another (village-city or from one neighbourhood to another), they are confronted with different people, some of whom may exercise violence against them. However, the study findings show that people who exercise more violence against adolescents in the community are exactly their peers. Approximately 4 out of 10 adolescents or (39.8\%) reported that have experienced violence from their peers. In this case, more are male peers the ones who make up the largest group of people who use violence $(28.5 \%)$, unlike female peers who exercise significantly less violence $(11.3 \%)$. After the peers, there are adults, from whom adolescents have experienced more violence in the community $(29.7 \%)$, where again comparing the gender, results that male gender are the ones that most often exercise violence $25.8 \%$, unlike female who only in $3.0 \%$ of cases exercise violence against adolescents in the community. Somewhat less violence in the community adolescents have experienced from different groups or bands operating in the city or city's areas (20.9\%), unlike $9 \%$ of adolescents who reported that they have not experienced violence from others in the community throughout their lives.

\section{Relationship between types of violence and the demographic characteristics of adolescents}

To measure the relationship between the types of violence experienced in the community and the demographic characteristics of adolescents, initially was tested if the data have normal distribution. This was done by the Kolmogorov-Smirnov test, which resulted that generally we have data that does not have normal distribution and consequently to understand these relationships are used non-parametric tests Mann-Whitney-U and Kruskal Wallis - H, which are equivalent to parametric T-Test and One Way Anova tests. 
Table 1.

Mann Whitney $U$ test - The relationship between the Types of Violence and Gender

\begin{tabular}{|c|c|c|c|c|c|c|}
\hline Types of violence & Gender & $\mathrm{N}$ & Mean Rank & Sum of Ranks & $\mathrm{U}$ & $p$ \\
\hline \multirow{2}{*}{ Psychological Violence } & W & 309 & & & \multirow{2}{*}{44839.5} & \multirow[t]{2}{*}{.246} \\
\hline & M & 299 & 299.97 & 902290.5 & & \\
\hline \multirow{2}{*}{ Violence against the property } & W & 309 & 313.49 & 97181.0 & \multirow{2}{*}{43714.0} & \multirow[t]{2}{*}{.159} \\
\hline & $\mathrm{M}$ & 299 & 296.20 & 88584.0 & & \\
\hline \multirow{2}{*}{ Physical Violence } & W & 309 & 276.53 & 85724.0 & \multirow{2}{*}{37519.0} & \multirow{2}{*}{.000} \\
\hline & M & 299 & 337.71 & 101854.0 & & \\
\hline \multirow[b]{2}{*}{ Sexual Violence } & W & 309 & 309.12 & 96446.0 & \multirow[b]{2}{*}{45358.0} & \multirow[b]{2}{*}{.516} \\
\hline & M & 299 & 301.71 & 89909.0 & & \\
\hline
\end{tabular}

When we talk about violence against adolescents in the community, must be emphasised that adolescents' gender does not seem to be decisive in terms of a certain level of violence exercised against them. On the other hand this can be said about psychological violence $(U=44839.5, z=-1.161, p=0.246>$ $\alpha=0.05)$, violence against the property $(\mathrm{U}=43714.0, \mathrm{z}=-1.407, p=0.159>\alpha=0.05)$ and sexual violence $(U$ $=45358.0, z=-650, p=0.516>\alpha=0.05)$. This means that in all these three types of violence, no difference in the level of violence suffered by adolescents in the community in terms of adolescents' gender.

However, this cannot be said of physical violence because the Mann Whitney - U statistical test shows that the difference between girls and boys regarding the level of physical violence suffered by adolescents in the community is meaningful on statistical aspect $(U=37519.0, z=-4.854, p=.000001<\alpha=$ 0.05). From the mean rank, is seen that the boys are more exposed to physical violence (337.26) compared to girls (276.53). In this case, we may emphasise that there exist statistically significant differences in the level of physical violence suffered by boys and girls in the community. 
Table 2.

Mann Whitney U Test - The Relationship between the Types of Violence and Residence (Rural - Urban)

\begin{tabular}{llllllc}
\hline Types of violence & Residence & N & Mean Rank & Sum of Ranks & U & $p$ \\
\hline \multirow{2}{*}{ Psychological Violence } & $\mathrm{U}$ & 478 & 311.94 & 150354.0 & & .058 \\
& $\mathrm{R}$ & 130 & 286.34 & 37224.0 & 28709.0 & \\
\hline Violence against the property & $\mathrm{U}$ & 478 & 308.90 & 147963.0 & 29267.0 & .223 \\
& $\mathrm{R}$ & 130 & 290.63 & 37782.0 & & \\
\hline \multirow{2}{*}{ Physical Violence } & $\mathrm{U}$ & 478 & 313.36 & 150724.0. & 28208.0 & .036 \\
& $\mathrm{R}$ & 130 & 281.33 & 36954.0 & & \\
\hline \multirow{2}{*}{ Sexual Violence } & $\mathrm{U}$ & 478 & 306.48 & 146802.0 & 30907.0 & .744 \\
& $\mathrm{R}$ & 130 & 301.93 & 39553.0 & & \\
\hline
\end{tabular}

Against adolescents who come from the village and those coming from the city are practically exercised almost the same levels of psychological violence, violence against property and sexual violence. The differences that exist between village and city's adolescents in relation to the suffered level of psychological violence, violence against the property and sexual violence are not statistically significant (psychological violence $U=28709.0, \mathrm{z}=-1.219, p=0.058>\alpha=0.05$; violence against the property $U=$ 292267.0, $z=-1.219, p=0.223>\alpha=0.05$; sexual violence $U=30907.0, z=-0.327, p=0.744>\alpha=0.05$ ). In these cases we say that the adolescents' residence does not have any impact on the level of violence suffered in the community for these three types of violence.

However, the residence seems to be influential when talking about the level of physical violence suffered in the community. From the mean ranking, comes out that adolescents from the city have higher rank (313.36), compared to adolescents from the village (281.33). The difference is also confirmed by the statistical test $(U=28208.0, z=-2.100, p=0.036<\alpha=0.05)$. Based on this level of statistical significance, we can say that adolescent's residence have an impact on the level of physical violence suffered in the community. 
Table 3.

Kruskal Wallis H Test - The Relationship between the Types of Violence and Age

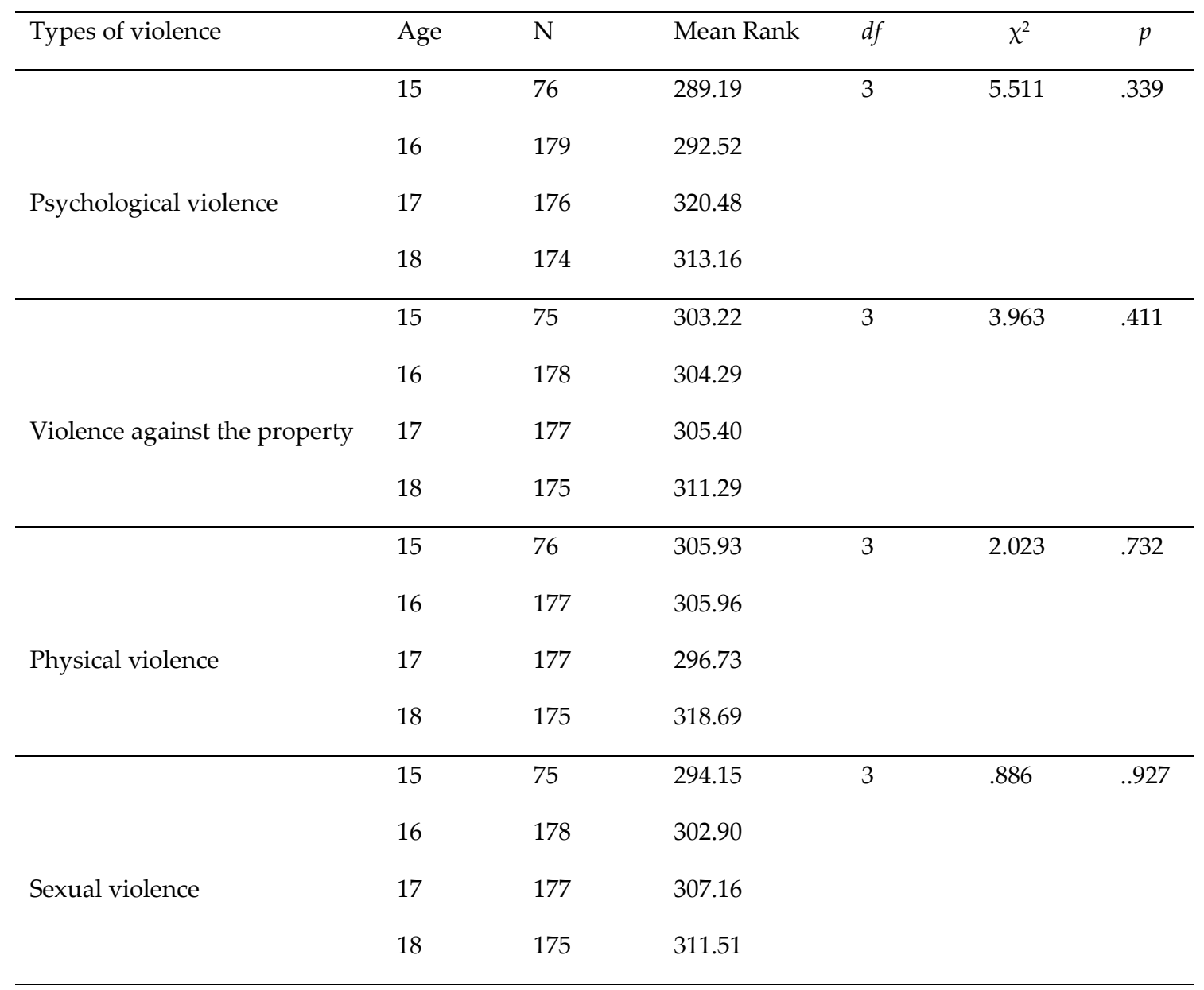

But, if we look at the results of the Kruskal Wallis $\mathrm{H}$ test, regarding the relationship between types of violence and age of adolescents, it turns out that in contrast to the differences that exist in the mean ranking, these differences results not to be statistically significant, which means that types of violence experienced in the community are not related with the age of adolescents $(p>\alpha=0.05)$.

\section{DISCUSSION}

With the community, in the study is meant the environment outside the home and school, such as neighbourhoods, streets, various objects, parks, pubs, shops, during various out-of-school activities etc. Surely, being such an environment with impossible opportunity to be controlled, the probability of suffering violence in these environments is extremely huge by every person, especially from adolescents. This, in fact, is proven by the study. If we generalize the results, we can say that even in the 
community, the violence is very prevalent to the level that almost every adolescent during his life has suffered one or more types of violence.

However, the high numbers of suffered violence also find support in the literature, especially if we look at the type of violence. Such levels of violence are also roughly elicited by O'Keefe (1997), but by putting physical violence on the first place, followed by violence against the property then psychological violence (harassment) against children and sexual violence at the lowest level. While, Hamby et al. (2005) and Ellonen et al. (2008) stressed psychological violence such as threat, intimidation and harassment, and conventional crimes involving property damage such as theft, vandalism and robbery, as a most prevalent types of violence against adolescents in the community. Even other studies, especially those based on the Juvenile Victimization Questionnaire (JVQ) questionnaire; have derived high percentages of violence against children in the community, on the other hand physical violence or violence against property are put on the higher percentage (Finkelhor \& Ormrod, 2000; Finkelhor \& Dziuba - Leatherman, 1994). So, we may conclude that violence against adolescents is at a high prevalence in the community, but by the frequency it is at very low level.

Regarding persons who exercise more violence in the community, the study derives peers as the group of people who have exercised more violence against their peers in general, dominated by male peers' gender. After peers, the other group of people from whom adolescents suffer more violence in the community are adult, where again is dominated by male adults. And the third group, which also poses a risk to children, are the various bands and groups operating in the community. Tolman and Guerra (1998) consider that during the adolescents' years the most frequent perpetrators of violence are their peers. The fact that even in this study, the largest group of people who exercise violence in the community make up peers, shows that relationships among peers are often violent and are build based on violence, moreover they use violence to resolve conflicts (Krug, 2002), or even to achieve their goals. This also shows the unsatisfactory level of the Kosovo Education System, the system that somehow is promoting violence in general. Even though violence exercised by peers is considered to be less serious than the one caused by adults (Finkelhor, 2008). However, if we look at the second group of persons who have exercised violence, that are adults, it shows that still dominate the values under which adults have priority over the children, so adults use their forms (violence) to resolve conflicts in relation to children. Anyway, from adults and peers mix, are formed groups or bands of youths operating in the neighbourhoods and cities, which are in fact the product of the whole situation: social exclusion, inadequate education system, poverty level and socio-economic conditions that reign in Kosovo. All these, in fact, indicate an unfavourable environment in which the child grows in Kosovo, which is largely characterized as being violent.

The results of the study have shown that when we talk about the subjects' demography, particularly gender, age and residence, their relationship to violence exercised in the community against adolescents is statistically significant, only to some types of violence. From the demographic characteristics, gender has resulted with statistical significant impact only when talking about physical violence experienced in the community ( $\mathrm{p}<\alpha=0.05$ ), but not when talking about other types of violence. In this regard, Salzinger et al (2002) considers that "the circumstances in which an adolescent is victimized in the community are different for boys and girls". When we are in these circumstances, Whitbeck and Simons (1990) found three gender differences associated with the victimization in the community, dealing with: 
domestic violence, peers associated with deviant behaviour and the frequency of leaving the home, but this study neither has taken nor addressed these factors.

Also, the study resulted that residence is a factor with significant statistical impact when talking about physical violence in the community, but not for other types of violence. Surely, this can be explained by the fact that in the city the population is much more heterogeneous, life is much more dynamic, social conflicts are bigger; all these have resulted in the study. Even life in a community, such as the capital is, is filled with many situational factors (moments) that may suddenly involve children in violent events (Pinheiro, 2006). On the other hand, starting from the fact that in the study has taken part age group of adolescences (15-18 years), in some ways everyone is going through a cycle of violence in society, involving all ages of adolescence.

The study on violence against adolescents in the community has its limitations. The first limitation has to do to sample selection where the study involved only adolescents aged 15-18, who come from Pristina high schools. The limitation impacts in the generalization of the findings, since they cannot be generalized for the whole of Kosovo.

The other limitation is related to the methodology, respectively the use of the quantitative method. Results could have been more valuable, if quantitative data would have been combined with qualitative data that could be obtained through qualitative methods such as interviews, focus groups, and so on. However, these limitations do not decrease the value of the study, especially if we consider that sampling is done by strict observation of the sample selection criteria, by the simple random probability method. In addition, this study being part of a more comprehensive study of violence against children in Kosovo made possible for data to be more comparable, more reliable and more representative for the entire target population.

Based on the study findings, which point out a high prevalence of violence against adolescents in the community and based on the fact that peers are the most frequent perpetrator of violence, several recommendations are given, which are addressed to the institutions and responsible persons:

- Is recommended to raise awareness of society in general, especially awareness of youth about violence, negative effects and its prevention. This can be done through media and awareness campaigns, but also by working harder in schools.

- Since violence mostly comes from peers, is recommended that all schools develop and adapt educational programs against violence, through the use of alternative non-violent methods of communication, negotiation, conflict resolution and positive discipline.

- Is recommended to create community-friendly places for children and adolescent. This can be done by creating as many special places as possible that are dedicated to adolescents to play and do other activities, through the monitoring of the places by volunteers or other persons.

- Is recommended more organized sports, cultural, social and other activities, thus their free time will be better organized. Such activities should be community-based and supervised, but may also be linked to other strategies, aimed to prevent violence, especially those with school-based, in order to strengthen protective factors such as self-confidence and increasing potential of adolescents to prevent violence. 


\section{REFERENCES}

Ellonen, N., Käriäinen, J., Salmi, V., \& Sariola, H., (2008). Violence against children and adolescents in Finland. National Research Institute. Research of Legal Policy. Communications no. 87

Finkelhor, D. (2008). Childhood victimization. violence, crime, and abuse in the lives of young people. Oxford University Press. Oxford, New York.

Finkelhor, D., \& Dziuba-Leatherman, J. (1994). Children as victim of violence: A national survey. Pediatrics, 94(4), $413-420$.

Finkelhor, D., \& Ormrod, R. (2000). Juvenile victims of property crimes. (NCJ184740). Washington, DC: U.S. Department of Justice, Office of Juvenile Delinquency and Prevention

Finkelhor, D., Ormrod, R. K., Turner, H.A., \& Hamby, S.L. (2005). Measuring poly-victimization using the Juvenile Victimization Questionnaire. Child Abuse \& Neglect, 29, 1297-1312.

Finkelhor, D., Turner, H., Ormrod, R., Hamby, S., \& Kracke, K. (2009). Children's exposure to violence: A comprehensive national survey. Juvenile Justice Bulletin.

Hamby, S. L., Finkelhor, D., Ormrod, R., \& Turner, H. (2005). The Juvenile Victimization Questionnaire (JVQ): Administration and scoring manual. Durham, NH: Crimes against Children Research Centre.

Krug, E. G., Dahlberg, L. L., Mercy, J. M., Zwi, A. B., \& Lozano. R. (Eds). (2002). World report on violence and health. Geneva, World Health Organization.

Margolin, G., \& Gordis, E.B., (2004). Children's exposure to violence in the family and community. American Psychological Society, 13(4), 152 - 156.

O'Keefe, M., (1997). Adolescents' exposure to community and school violence: Prevalence and behavioral correlates. Journal of Adolescent Health, 20, 368 - 376.

Pinheiro, P. S. (2006). World report on violence against children. Geneva. Published by the United Nations Secretary-General's Study on Violence against Children. Geneva, ATAR RotoPresse SA.

Salzinger, S., Feldman, R. S., Stockhammer, T., \& Hood, J., (2002). An ecological framework for understanding risk for exposure to community violence and the effects of exposure on children and adolescents. Aggression and Violent Behavior, 7, 423-451.

Sheidow, A. J., Garman-Smith, D., Tolan, P. H., \& Henry, D. D., (2001). Family and community characteristics risk factor for violence exposure in inner-city youth. Journal of Community Psychology, 29(3), 345-360.

Tolan, P. T., \& Guerra, N., (1998). Societal causes of violence against children. In: Trickett, P. K. and Schellenbach, C. J. (Eds.). (1998). Violence against Children in the Family and the Community. Washington, DC, US: American Psychological Association.

Whitbeck, L. B., \& Simons, R. L, (1990). Life on the streets: The victimization of runaway and homeless adolescents. Youth and Society, 22, $108-125$. 